\title{
Global Emissions Trading: A Post-Kyoto Proposal
}

\author{
Warwick J. McKibbin
}

\begin{abstract}
A T a conference held in Kyoto, Japan, in December 1997, the Parties to the UN Framework Convention on Climate Change agreed to a Protocol to
reduce global greenhouse emissions. Although heralded by many as a breakthrough in climate change policy, the Protocol is fundamentally flawed and in its current form will probably collapse if adopted. Its flaw is that the main focus is on achieving rigid 'targets and timetables' for emissions reductions at any cost rather than on substantial reductions in emissions at reasonable cost.
\end{abstract}

A good deal of uncertainty surrounds the costs and benefits of cutting greenhouse emissions; yet the Kyoto Protocol forces emissions back below 1990 levels without regard to the costs or benefits of doing so. Current evidence does not give clear support to a policy of holding emissions constant, let alone reducing them significantly. The costs and benefits of the Kyoto targets are not known with much precision; but most studies of costs of stabilisation arrive at estimates that are higher than the highest estimates of benefits. Moreover, it would be necessary to start to pay these costs now in order to avert damages far in the future. Given these considerations, it is difficult to believe that the United States Senate would ratify a treaty based on reducing greenhouse gas emissions below 1990 levels. There is, however, enough evidence to make a clear case for taking steps to slow the growth of greenhouse emissions. A better policy would focus on this more modest goal.

The move away from uniform targets for every country occurred at the Kyoto meeting because they were correctly seen to be very inefficient and politically infeasible. A crucial, but mostly ignored, issue is that any fixed targets, even differentiated targets, are likely to be inefficient because their costs over the long period of time being discussed are not known.

The post-Kyoto negotiations are now focused on attempting to make the problematic rigid target approach work by using economic instruments to minimise the efficiency losses from the agreement. In principle, these instruments look promising; indeed, the Kyoto Protocol explicitly incorporates the idea of using global

\footnotetext{
${ }^{1}$ See McKibbin and Wilcoxen (1997a) and Kopp et al. (1997) for arguments about the difference between price and quantity caps under uncertainty.
}

Warwick McKibbin is Professor of International Economics in the Research School of Pacific and Asian Studies, The Australian National University, and Non-Resident Senior Fellow at The Brookings Institution, Washington DC. 
emission trading permits or umbrella groupings of permit traders as a way to implement the Protocol. Unfortunately, while the advantages of a permit trading system at the domestic level is well established through other emissions trading schemes (such as the US sulphur dioxide scheme), and the global schemes seem theoretically sound, few researchers have understood the adjustment problems involved in implementing such a proposal. ${ }^{2}$ McKibbin and Wilcoxen (1997a, b) point out that a global emission permit trading system with caps on the number of permits (that is to say, an explicit and binding emission target) is a dangerous path to take because, under some scenarios for the evolution of the global economy, the Protocol may be abandoned because of economic and political problems outlined below. In an attempt to overcome the potential flaws in this scheme, we have proposed an alternative policy that would achieve real greenhouse gas reductions without the potentially disruptive political and economic problems of a global permit trading scheme that is built around fixed targets and timetables. This is a globally coordinated system of domestically implemented permit trading schemes with a fixed common permit price across all countries. Richard Cooper (1996) has called this an 'agreed actions' rather than an 'agreed targets' approach. The idea is to produce a system that falls between the extremes of rigid targets and inaction on climate change policy.

\section{How Do Permit Systems Work?}

The basic idea behind a tradeable permit system is simple. Any firm emitting carbon dioxide (or the carbon dioxide equivalent of a broader range of gases) would be required to own permits equal to the amount of carbon it produces. For example, a firm emitting 100 tons of carbon would have to own 100 permits. The permits would be allocated among countries by treaty, and each government would decide how to distribute its permits domestically. Once distributed, the permits could be bought and sold without restriction on a world market. It would be illegal to burn fossil fuels without having purchased a permit, and it would be up to each government to enforce the treaty within its own borders.

Permit systems have three key features as a method of pollution control. First, they provide a firm upper bound on emissions. This feature makes permits attractive to those who believe that decisive action needs to be taken on climate change.

Second, because the permits can be traded, pollution abatement will occur at the minimum possible cost to the economy. Firms that can clean up cheaply will carry out the abatement: they will be able to make a profit by cutting their emis-

\footnotetext{
${ }^{2}$ See Hartley (1997) and Cornwall et al. (1997) for an overview of permit trading and its desirable properties. Like most studies, these papers ignore the international economic adjustment problems.

${ }^{3}$ In addition to the proposal forming the basis of this article, Anderson and McKibbin (1997) estimate that a significant reduction in greenhouse gas emissions can be achieved at low cost by removing existing distortions in world coal markets. Such a policy should precede the implementation of the proposal discussed here.
} 
sions and selling their surplus permits. Firms that find it very expensive to reduce emissions will buy permits instead.

Third, permits will ensure that the marginal cost of reducing carbon emissions is the same in all countries that participate in the scheme. In other words it would cost the same to remove a unit of carbon from each country participating, so no lower-cost options will remain.

If a global permit system were implemented following the Kyoto Protocol, countries would presumably be allocated an initial stock of permits equal to their targets. For example, Australia would receive permits equal to 108 per cent of 1990 emissions whereas the United States would receive permits equal to 93 per cent. These would be allocated within countries, and firms could trade with one another in a global market. Given that the marginal abatement costs (the incremental cost of reducing emissions) are estimated to differ across countries, ${ }^{4}$ the permit price would be somewhere between the lowest and the highest marginal abatement costs.

A global permit trading scheme appears to be a very attractive way to implement the Kyoto Protocol. It performs well when run through global models under multiple scenarios, and clearly minimises abatement costs in the longer run. However, a number of potential problems can be identified that are related to the nature of the adjustment path rather than the long run.

\section{What Could Go Wrong in Practice?}

Permit systems have worked well when used to control domestic environmental problems. The best-known example is the sulphur emissions trading scheme introduced by the 1990 amendments to the United States Clean Air Act. It has been a tremendous success: electric utilities, the principal industry affected by the programme, have been able to reduce the cost of controlling sulphur emissions to onetenth of the minimum cost projected when the act was adopted. For controlling carbon dioxide emissions in an international context, however, several practical problems arise that ensure that a treaty based on an international permit trading scheme would be very difficult to ratify or implement in the US.

A fundamental problem with a conventional global permit system with a fixed supply of permits is that it could generate large transfers of wealth between countries. This is not likely to be a problem for a system including only the developed Annex I countries. But it becomes a more serious potential issue when the system is expanded to include the major developing countries. Supporters of a permit system regard the wealth-transfer properties of the permit scheme as an advantage because it would allow developed countries to compensate developing countries for reducing their emissions. This would be a significant political problem for the US Congress. But, more important, it could put enormous stress on the world trade system. The balance of trade for a developed country importing permits would deteriorate substantially. This would lead to substantial volatility in exchange rates and distortions in the world trade system. Equally serious problems would be cre-

\footnotetext{
${ }^{4}$ See ABARE (1997) and McKibbin and Wilcoxen (1997c).
} 
ated for developing countries. Massive exports of permits would lead to exchange rate appreciation and a decline or collapse in exports other than permits.

Another problem is that the permit revenue for developing countries comes with strings attached: much of it would have to be invested in improved energy technology in order to reduce emissions and free up the permits in the first place. This is unlikely to be an ideal strategy for long-term economic development and would make the policy unattractive to developing countries.

In fact, developing countries have been so unenthusiastic about the policy that the Kyoto meeting produced support for an umbrella group to trade emission permits (including Australia, New Zealand, Canada, Japan, Russia, Ukraine and the US). However, this is a compromise that significantly weakens the main reason for having internationally tradeable permits: the potential gain from trade in emissions rights between industrialised and developing countries. Permit trading would do little to lower abatement costs when the participating countries have fairly similar marginal abatement costs. Moreover, this umbrella system may not even reduce emissions, because Russia and the Ukraine are well below their 1990 emission levels and would be able to sell their unused permits within the umbrella group. In that case, the permit system would really amount to nothing more than an elaborate accounting mechanism for counting increases in emissions in countries like the US against the 1990 allocation for Russia; there would be little or no overall reduction. But under a plausible alternative scenario in which Russia grows strongly between now and 2008, the demand for permits within Russia would increase, sharply driving up the umbrella price of permits. This could add an ironic twist to an international permit policy: if Russia were to grow quickly, the US could soon become the developed world's low-cost emissions abater. In that case, the US would be a net seller of permits, and the rest of the industrial world would end up paying it to reduce its emissions. Under the scenario outlined, this is exactly the outcome that efficiency would dictate; but it would be politically fatal to the Kyoto Protocol in the US. Most important, serious greenhouse abatement will only occur in a system that includes developing countries. Whatever emerges from post-Kyoto negotiations should have this as the paramount objective.

Another problem with the Kyoto Protocol and any conventional permit trading system under a fixed target is that no individual government would have any incentive to police the agreement. It is easy to see why this is so: monitoring polluters is expensive, and punishing violators imposes costs on domestic residents in exchange for benefits that will accrue largely to foreigners. Governments would be strongly tempted to ignore firms exceeding their emissions permits. For the treaty to be viable, however, each participating country would need to be confident that all of the other participants were enforcing it. It is clear that such a system would require an elaborate and expensive international mechanism for monitoring and enforcement.

A final problem is that the supply of permits would be from each country participating and hence any country that cheats on the system will potentially undermine the value of permits for the entire system. Once the value of permits becomes highly uncertain, the system is vulnerable to collapse. To see this, consider the case 
of government bonds issued by different countries. These are essentially the same instruments, but each is priced differently in world markets purely because government bonds are issued by different governments. Thus, different sovereign risks are priced into government bonds from different countries precisely because there are different degrees of uncertainty about the ability of governments to honour these assets. Now consider the potential disruption to global bond markets if all countries were able to issue exactly the same bond that was redeemable in any other country. The system would be vulnerable to collapse if one country behaved inappropriately and undermined the value of all government debts. Thus, a world permit system with a fixed supply of permits and a variable permit price would be very difficult to hold together because it would require enforcement procedures and a rule of law that currently do not exist at the global level.

All in all, an international permit system aimed at a fixed target for greenhouse emissions is unlikely to be politically viable in developed countries, could distort or compromise the world trade system, would be unattractive to developing countries, and would be difficult to monitor and enforce. It is an impractical policy focused on achieving an unrealistic goal.

\section{An Alternative to Fixed Targets}

McKibbin and Wilcoxen (1997a, b) have advocated a policy that gets around the potential problems of a global permit trading scheme discussed above. This a system of internationally coordinated but domestically administered permit trading systems with a fixed price in each system. In many ways our approach seems like a small movement away from the global permit scheme with a fixed quantity of permits, which retains many of the advantages but removes crucial problems. Despite the apparent similarities, our approach is philosophically far removed from the degree of centralisation implicit in a global permit scheme, which has very different political implications. ${ }^{5}$ Our proposal, as originally designed, is an internationally coordinated system of national permits and emissions fees for carbon dioxide, although it could easily be extended to incorporate the six greenhouse gases identified in the Kyoto Protocol. ${ }^{6}$ Under this system, all emitters would be required to own permits equal to their total emissions of these gases.

There would be two stages of permit distribution. In the first stage, countries would be allowed to distribute a specified number of permits to their domestic emitters in any way they liked, including handing them out for free. To minimise administrative costs, the permits would be based on the emission of carbon at the

\footnotetext{
5 Our proposal has become known as the McKibbin-Wilcoxen Proposal in the international debate; but, for whatever reason, has been called the McKibbin Tax in the Australian debate: inappropriately in my view, because most of the revenue from the purchase of permits is a transfer within industry not between industry and the government. Only a small part of additional permits sales accrues to government.

${ }^{6}$ Carbon dioxide, methane, nitrous oxide, hydrofluorocarbons, perfluorocarbons and sulphur hexafluoride.
} 
original source of energy such as the coal mine and oil and gas extraction industries. Although this is where the permit is required, these producers do not bear the full burden of the cost, since this will be passed through the production and consumption chains with some portion of the permit price being reflected in the final price to end users of carbon-intensive products.

The key to our system is that, rather than allow permit trading to set the market price, the price of permits will be fixed by international agreement. The market trading will then determine where abatement occurs, but at the fixed price. We propose a fixed permit price of US $\$ 10$ a ton of carbon, because this is well below the price that most models estimate a stabilising permit price would be. So at the fixed price, there will be an excess demand for permits. Once a firm receives an initial allocation of permits from its government, the firm will have to decide whether to buy additional permits, sell some of its allocation, or stay with exactly the number it was given. If it does not buy or sell permits, it can continue with its existing practices at no additional cost (although there is a significant opportunity cost from not selling permits). If it needs to increase its carbon-emitting activities, however, it will have to buy additional permits at a price of US $\$ 10$ a ton, giving it a clear incentive to avoid increases in emissions. At the same time, if the firm could reduce its emissions, the permit system would give it a strong incentive to do so: avoided emissions could be sold on the permit market at a price of $\$ 10$ a ton. For example, if an electric utility could shift some of its load from coal to natural gas for a cost of $\$ 6$ a ton of carbon, it could emit less carbon and make a profit of $\$ 4$ a ton by selling its excess permits. Indeed, many firms have claimed they are willing to undertake low-cost carbon abatement. The permit system we propose will reward firms for these endeavours. The more effort a firm puts into reducing carbon emitting activities at low cost, the higher its profits will be.

After these permits are allocated within each country an unlimited number of additional permits could be purchased from each government by domestically located emitters at a stipulated international price of US\$10 a ton. Thus, the price is held by governments being willing to sell additional permits to satisfy the excess demand emerging from permit trading among domestically located firms. Because the total number of permits can rise if abatement turns out to be expensive, the policy has safeguards that would limit the economic damage that the policy could inflict. Yet we have chosen a price which most studies estimate will generate a demand for permits in excess of the initial allocation (this could be based on 1990 emissions or the Kyoto targets but would be negotiated).

Since the policy does not focus on achieving a specified target at any cost (indeed the cost is known with certainty), such a system would be far more likely to be ratified, and by more countries. This policy is not simply a uniform carbon tax, as it is often portrayed. Only marginal emissions above the target are subject to a direct charge (the price of permits); but most of this is a transfer within industry rather than between industry and government. Indeed, existing emitters are implicitly given subsidies to change their behaviour because the opportunity cost of continuing with their activities is the permit price. If firms do nothing, they are not 
subject to any direct cost increase but are awarded profit in proportion to their success at reducing emissions.

Although at first sight it appears that existing industry and new industry are treated differently, this is not the case. Existing emitters would experience a decline in the value of capital. They will have to change their capital stock over time. These existing emitters receive lump-sum compensation for the change in the value of existing capital stock that the permit system would cause. This compensation is proportional to the amount of abatement achieved. A unit of carbon emitted will cost both new and existing firms the same because new firms must buy the permit, but existing firms must decide whether to keep the permit at the cost of the permit price or to reduce emissions. Either way, the permit price will affect the costs of the two types of firms in exactly the same way.

In principle, this system could also deal with the issue of sinks of greenhouse gases by allowing producers of sinks (land-use changes, tree planting and so forth) to be awarded permits for their activities that they can then sell into the permit market. There are serious issues of measurement that need to be overcome to ensure that the system is not debased; but in principle a generalised McKibbin-Wilcoxen system would be possible and would be more feasible in each domestic system than at the global system because of differential measurement of sinks across countries (though it is not be considered in this article).

The McKibbin-Wilcoxen proposal as extended here has a number of advantages. First, the same price will be charged for each new permit in each country as well as for any permits that are traded in domestic permit markets. Thus, the marginal cost of reducing carbon emissions will be equalised within and across all countries that participate. This makes the system efficient because the cheapest emissions reductions will be undertaken first. Environmentalists and engineers often argue that many low-cost options are available for reducing energy demand. If so, these low-cost options will be exploited under this policy, without needing to be specifically identified in advance by the government. On the household side, for example, the increase in energy prices will encourage households to demand more energy-efficient vehicles and appliances.

Second, the policy contains built-in mechanisms to encourage enforcement. Governments will have an incentive to monitor the system because they will be able to collect revenue from selling permits. Firms will have an incentive to monitor one another because any cheating by one firm would put its competitors at a disadvantage and would also affect the value of permits held by other firms.

Third, the system is flexible and decentralised. New countries can join by setting up their own permit systems and agreeing to charge the stipulated world price for additional permits.

Fourth, transfers associated with the permit system are largely between firms or between firms and households, rather than between the private sector and the govermment. The proposal also minimises transfers across borders, avoiding serious economic and political problems. Unlike the experience of the 1970s, increases in 
energy prices under this policy would not lead to massive transfers of wealth between countries.

Fifth, the policy also could be revised easily as more information becomes available. After setting up the system and agreeing on the price of permits, participating countries could meet every five years to evaluate the extent to which carbon emissions have been abated as well as to re-evaluate the extent of climate change and its consequences. If it becomes clear that more action is required, the permit price could be raised. If climate change turns out to be less serious than it appears today, the permit price could be lowered. To minimise the costs of these price changes, future markets could be developed in permits so that risks are effectively shared.

Sixth, if any country decided to renege on its commitments, this would only mean emissions globally would be higher than otherwise, but the value of permits in other countries within the system would not be undermined and the system could hang together as countries leave and enter the system.

Overall, the advantage of the McKibbin-Wilcoxen proposal for a domestically managed, but internationally coordinated, permit and fee system over the targets and timetables approach of the Kyoto Protocol is simply that it is far more practical. It is more likely to be ratified by key countries because it limits the cost of compliance and does not require governments to commit themselves to achieving a given target at any cost. It is more likely to be acceptable to developing countries because it is not a Western-controlled centralised system. It is transparent to households and firms globally because it spells out exactly how the policy will work, rather than specifying the target and leaving the policy undefined. It is more credible than a targets and timetables policy because it is not so draconian that countries will be tempted to renege under extreme future scenarios, and because the revenue from selling additional permits will give governments an incentive to enforce the agreement over time. Existing industry is less likely to oppose it because compensation is built into the system. Moreover, because it contains a mechanism for limiting economic costs, the risk of setting ambitious emissions targets, which could significantly reduce economic growth if abatement proves to be expensive, is eliminated. This would remove the single most important obstacle to reaching a realistic international climate policy.

Most important, our system explicitly deals with the uncertain nature of the climate change problem and allows plenty of flexibility when new information emerges on the costs of abatement, changes in climate and new developments in climate science. It is also more likely to survive the political uncertainties of changing country commitments over time.

\section{What Should Australia Do Now?}

Australian policy-makers now face a dilemma. They have signed a Protocol which is subject to a great deal of uncertainty about ratification by key countries. A meaningful agreement hinges on how developing countries are included and this will become clearer in Argentina in November 1998 with the fourth meeting of the Conference of the Parties to the Framework Convention. If the Kyoto Protocol 
does proceed, action will need to be initiated in Australia because, despite beliefs to the contrary, Australia has a good deal of abatement to be implemented by 2008 . My research suggests that carbon dioxide emissions from fossil fuel use will reach 150 per cent of 1990 levels by 2010 , using plausible assumptions (with a great deal of uncertainty around this number in both directions). Adding other sources of emissions complicates the actual emission calculation, and incorporating sinks further complicates the extent of adjustment required. Nonetheless, Australia's target of 108 per cent of 1990 levels by between 2008 and 2012 will potentially require significant policy changes.

If Australia is to participate in an international agreement like the Kyoto Protocol, action should start as soon as possible, but after the Protocol is ratified by the US. This is particularly important for industries that need to make long-term investment decisions. In the meantime, Australia should lobby the international community to move away from the fixed targets approach enshrined at Kyoto towards action based on permit trading with a fixed low price. The proposal for a fixed-price scheme set out here could be made consistent with the Framework Convention on Climate Change. There could be a clear statement that the goal of the policy is a reduction in emissions. To achieve this, every five years countries would meet to consider the success of the permit trading schemes in reducing global emissions and then negotiate a price for permits that would lead to convergence of emissions towards the stated goal. This learning by doing approach to international policies is a far more sensible way to proceed.

There is already considerable interest in the McKibbin-Wilcoxen proposal (or variations of it) at the international level, although most negotiators argue that it is currently infeasible to change direction so fundamentally in view of the current state of negotiations.

If the Kyoto Protocol is ratified by the US, and the world continues to use rigid targets, it would be sensible for Australia to start a domestic permit trading system. This would place it in a good position if and when an international permit trade system is implemented. There is, however, a serious problem that should be considered. For carbon emissions alone, we estimate that marginal abatement costs for Australia are high and certainly higher than for the US. Thus, the price of permits in an Australian domestic system would be expected to be much higher than the price in a system that included the US, which has low estimated marginal abatement costs, or even one that included Russia, which would bring a significant volume of essentially 'free' permits to the system. After all, if the prices of an Australian-only system and a wider group of countries were the same, a permit trading system would be unnecessary because there would be no gains from trade across national borders! So a permit system within Australia with a cap on permit quantities equal to the Kyoto emission targets could be a very bad idea in the near term because any subsequent participation in a multi-country system would most likely lead to a large fall in the permit price in the future. Why pay a high economic price in the short

${ }^{7}$ See McKibbin and Wilcoxen (1997c) for some estimates. 
term? If Australia is seriously going to reduce greenhouse emissions, an alternative approach would be to introduce a McKibbin-Wilcoxen system in Australia with a very low fixed permit price of, say, $A \$ 5$ a ton of carbon-equivalent emissions. Thus, the cost of abatement would be known and fixed for a period of several years. A low price with market-determined abatement would ensure less economic disruption than a market-determined price. The permit price could then be adjusted, either independently by Australia or as part of entering into a wider system with more countries.

Given the many uncertainties with the current state of negotiations, the international community may yet adopt the global system consistent with our proposal for a decentralised fixed-price permit trading system. It would be sensible to implement this in Australia sooner rather than later. Even if the international community continues to move towards a multi-country system with a fixed target for emissions, there is a strong case for implementing a fixed-price permit system in Australia in the short run. A domestic fixed-price system with a low initial price would minimise the costs to Australia during the transition from a domestic permit system to a global permit system.

\section{Summary}

The Kyoto Protocol is a bad outcome for global environmental policy. It has created a great deal of uncertainty about how and whether countries are going to achieve by 2008-12 the strict quantity targets that have been set. The international community had an opportunity to implement a credible instruments-based approach that would begin to reduce emissions at low cost wherever possible, in addition to giving flexibility to the time frame and burden-sharing arrangements. Policymakers now have to turn to economic instruments within a target regime that has many potential risks.

For researchers of climate change and for negotiators and bureaucrats, Kyoto was a full-employment contract for many years to come. For the world economy, it has presented many crucial challenges. Our goal should be to make the system that develops as decentralised as possible and to ensure that Australia does not commit to a significant loss in economic well-being while waiting for the other key countries to participate. If greenhouse gas emission reductions are to be pursued - and this will need to start soon if Australia is serious about the Kyoto Protocol - one way forward is a domestic version of the McKibbin-Wilcoxen proposal outlined in this article. In this case, a tradeable permit system could be implemented within Australia but with a very low fixed price for permits. The initial allocation of permits could be the Kyoto target. The market would then be used to determine the extent of abatement at a known cost. This begins the greenhouse reduction process at the same time as keeping costs low until the outcome of a decade of future negotiations is realised. 


\section{References}

Australian Bureau of Agricultural and Resource Economics (ABARE) (1997), The Economic Impact of Climate Change Policy, Canberra (Research Report No. 97.4).

Anderson, K. \& W. McKibbin (1997), 'Reducing Coal Subsidies and Trade Barriers: Their Contribution to Greenhouse Gas Abatement', Brookings Institution, Washington DC (Brookings Discussion Paper in International Fconomics No. 135); Centre for Fconomic Policy Research, London (Discussion Paper No. 1698); Centre for International Economic Studies, University of Adelaide (Seminar Paper 97-07).

Cooper, R. (1996), 'A Treaty on Global Climate Change: Problem and Prospects', mimeo, Harvard University, Cambridge, Mass.

Cornwall, A., J. Travis \& D. Gunasekera (1997), Framework For Greenhouse Emission Trading in Australia, Industry Commission, Canberra (Staff Research Paper).

Hartley, P. (1997), 'Can International Tradeable Carbon Dioxide Emission Quota's Work?', pp. 6982 in Managing Climate Change - Key Issues, papers from the APEC Studies Centre conference 'Countdown to Kyoto: Mandatory CO2 Emission Reductions', Monash University, Melbourne, 19-21 August.

Kopp, R., R. Morgenstern \& W. Pizer (1997), 'Something for Everyone: A Climate Policy that Both Environmentalists and Industry Can Live With', Weathervane, September 29; Resources for the Future home page - HYPERLINK htt://www.weathervane.rf.org/features/feature015.html • Washington DC.

McKibbin, W. \& P. Wilcoxen (1997a), 'A Better Way to Slow Global Climate Change', Brookings Institution, Washington DC (Brookings Policy Brief No. 17, June).

http://www.brook.edu/ES/POLICY/Polbrfl7.htm

- (1997b), 'Salvaging the Kyoto Climate Change Negotiations', Brookings Institution, Washington DC (Brookings Policy Brief No. 27, November).

http://www.brook.edu/ES/POLICY/Polbrf27htm

(1997c), 'The Economic Implications of Greenhouse Gas Policy', pp. 8-34 in H. English \& D. Runnals (eds), Environment and Development in the Pacific: Problems and Policy Options, Addison Wesley, Longman, Melbourne.

This article is a substantially revised version of a paper originally prepared for the APEC Studies Centre conference on 'Kyoto - The Impact on Australia', Melbourne, February 12-13, 1998. It draws significantly on ideas and papers developed jointly with Professor Peter Wilcoxen from the University of Texas, Austin. I have also benefited from comments and suggestion of anonymous referees. The views expressed are those of the author and do not in any way reflect the views of the above mentioned individuals or institutions nor the staff or trustees of the Brookings Institution or The Australian National University. All references to my research in this article can be downloaded from www.msgpl.com.au. 